\title{
The Idea of Contract in Japanese Law and Culture
}

\author{
Sara Landini \\ Department of legal studies, University of Florence
}

Follow this and additional works at: https://gensoken.toyo.ac.jp/japanese-society-and-culture

Part of the Contracts Commons

\section{Recommended Citation}

Landini, Sara (2021) "The Idea of Contract in Japanese Law and Culture," Japanese Society and Culture: Vol. 3 , Article 9.

DOI: $10.52882 / 2434-1738-0309$

Available at: https://gensoken.toyo.ac.jp/japanese-society-and-culture/vol3/iss1/9

This Article is brought to you for free and open access by Institute of Social Sciences. It has been accepted for inclusion in Japanese Society and Culture by an authorized editor of Institute of Social Sciences. 


\title{
The Idea of Contract in Japanese Law and Culture
}

\section{Sara Landini *}

\begin{abstract}
The paper deals with contract law in Japan in the perspective of law and litterature in order to better understand some basic concepts that actually are not a translation of western concept like good faith.
\end{abstract}

Keywords: Contract, Law, Good Faith, Giri, Jori, Theater

INDEX

1- Giri and Jory in private relationships.

2- Law and Theatre.

3- WA and Community.

4- The idea of contract.

5- Translation of Japanese contractual terms.

1. A contract is an agreement regulating inter individual relationships. In Japanese culture, three terms characterize the relational sphere and, therefore, the rules of conduct between individuals: "giri" or the set of behavioral rules inspired by ethical duties; the "jori" or the set of rules based on the sense of justice; the "wa" which means harmony, sense of community, peace and conciliation with others and which represents a key word of Japanese culture. In fact, the ideogram of “wa” 倭 has represented the idea of "Japan" for twelve centuries.

The "jori" is normally translated as "recta ratio" 1 . The scholars who have explored its role in Japanese legal culture have stressed that this concept more properly represents the sense of right and wrong that judges must understand and adopt in their decisions 2 .

Some scholars have defined the "jori" as "equitable interest" equating it to the equitable pronunciation of common law judges, in an attempt to give it a comprehensible definition for the western world.

It is, however, in my opinion, a dangerous combination. Jori is, in fact, a concept of Confucian derivation dating back to the Tokugawa period, better known as the Edo period (1603-1868), far removed from the conceptions of substantial justice of the contemporary western world ${ }^{3}$.

The "giri" concerns the set of duties, which arise from an interpersonal relationship, distinct from civic duties". In some cases it can be a question opposing systems, like the civic duty of freedom to vote

※ Professor at the University of Florence, Department of legale studies, Italy

1 Goodmann, The Rule of Law in Japan, Austin-Boston-Chicago-New York- The Netherlands, 2008, p. 312; Chianale, Giappone, in Noviss. Dig. Disc. Priv. sez. civ., IX, Torino, 1993, p. 5.

2 Röhl, History of Law in Japan since 1868, Leiden - Boston, 2005, p. 731; Id., Rechtsgeschichtliches zu jori, in H. Menkhaus, Das Japanische im japanischen Recht, München, 1994, p. 39 ss.; Bölieke, Die Bedeutung der Begriff jori für die japanische Rechtsquellenlehre, in Journal of Japanese Law, 1996, p. 7 ss.

3 Dean, Japanese Legal System, London-Sidney, 2002, p. 129 e 133 ss.

4 Naito, Edo, the city that became Tokyo: an illustrated history, Trad. Horton, Tokyo, 2003; CAROLI - GATTI, Storia del Giappone, Roma-Bari, 2009, $5^{\circ}$ ed., p. 95 ss. 
and the duty that one can have of returning a favor to a politician on the basis of the "giri"

The "giri", as a system of duties on which the sense of community and the sharing of values is based, is opposed to individual rights by attenuating their relevance and facilitating the mechanisms for settling disputes 6 .

2.

The system of duties of "giri" is already evident in the Edo period theater (1600-1868) and in particular in the literary expressions of the tradition of medieval storytellers and kabuki is.

In Japanese theater we find the main ideas to explain what is meant by "giri". As one of the scholars who contributed most to the spread of Japanese theatrical culture in Italy, states "in no other country in the world, as in Japan, theater reflects and summarizes, in its evolution, the history of civilization and indigenous culture, with all his aesthetic and religious experiences, with all his material and spiritual achievements" 7 .

The contrast between "ninjo" and "giri" is clearly present in the works of Chikamatsu Monzaemon sometimes defined as the Shakespeare of Japan for the centrality of his figure in the history of Japanese literature and for his creative force which opened up to a new period of the tradition of medieval storytellers which had been stagnating for some time, above all from a musical point of view.

Chikamatsu Monzaemon dared, in fact, to introduce "social dramas" in puppet theater which provides techniques and means of expression very different from the "kabuki" theater in which dramaturgy has more easily found expression.

Among his works in which the concept of "giri" is expressed, as opposed to "ninjo", we can particularly remember "Meido no hikyaku" (the courier of hell). The work tells the story of a man who works in the adoptive father's transport company and who steals the company to redeem his beloved woman who worked as a courtesan in a tea house. In the conflict between individual feelings and duties towards the adoptive father betrayed in trust, the man decides to kill himself.

Another famous work by the same author in which the contrast between "ninjo" and "giri" is well expressed is the "social drama" entitled "Double suicide of love in Sonezaki" (Sonezaki shinju) 1703.

The work is about Tokubei, a man who works in his adoptive father's soy sauce factory, who is also his uncle. The owner wants to marry his wife's granddaughter, but he loves O Hatsu a courtesan who is about to be redeemed by a samurai who wants to make her his wife or concubine. The two lovers in the conflict between their feelings and the duties of "giri" that bind the young man to his uncle, decide to commit suicide.

The words of the young Tokubei in the act of suicide are really significant: "No, I don't have to complain. As a child, I lost my parents and became a man thanks to the care of my uncle, who was a father for me. I have not rewarded the benefits I received, so I am reduced to this extreme”.

The gratitude due to his uncle is such as to overcome the unjust compulsion at the wedding. The

\footnotetext{
5 Sakurai, On to giri (On and giri), Tokyo, 1961, pp. 278-282.; Yasuda, Giri ni tsuite: nihon-shakai-ron nōto, (Studies on giri: notes on Japanese social theory ), in Gendai Shakaigaku (Modern Sociology), 1974, p. 179 ss.; Benedict, The Chrysanthemum and the Sword, Boston, 1946, in particular p. 133 ss.

6 Inako, Nihon-ho-nyumon (An introduction to Japanese law), Kyoto, 1981, p. 131 ss.

7 Muccioli, Il teatro giapponese, Milano, 1962, p. 138 ss.; Chamberlain, Moeurs et Coutumes du Japon, Paris, 1931, p. 435
} 
young man cannot complain that he is forced to commit suicide, but rather he must hope that his uncle may one day forgive him for failing to comply with his provisions.

Ihara Saikaku (1642-1693), revolutionary writer of the Edo period, is the author of the "Stories of moral obligations of the samurai (Buke Giri Monogatari)" (1688), an emblematic text on the impatence of moral values within the samurai caste, that of the samurai, governed by firm principles of ethics and respect for hierarchies.

One of the episodes concerns a young man who seeks revenge for his father murder. He met an older samurai and they became good friends. Only later the young man discovered that the elderly samurai was the murderer of his father by order of a feudal lord. Faced with the contrast between the personal feelings and the duties of the "giri" the two samurai can only find a solution in suicide.

"Wa" is also a central term in Japanese culture and literature.

The "wa" was first introduced into the constitution by Prince Shotoku in 600. In the prince's mind, what is now translated as the principle of harmony, was more specifically a state of order of the imperial system.

In the literary sphere the concept of "wa" is very present if one has regard to Japanese dramaturgy. The dramaturgical works are in fact normally characterized by a contrast between the characters of the theatrical action. In the No theater that express the concept of wa (which starts from the 14th century), a limited tonal scale is adopted, with long repetitive passages and there is no contrast between the characters. There is no opposition between a protagonist and antagonist, but a harmonic interplay between a protagonist (shite) and a deuterogamist (waki) whose function is to respond to the protagonist or to provide him with the opportunity to sing or dance. Both can then have companions. The contrasts typical of western dramaturgy are therefore lacking.

3.

The sense of belonging to the community is also linked to another characteristic of Japanese legal culture or to the tendency to settle conflicts in civil relations in a conciliatory way.

As is known, conciliation is a dispute resolution technique implemented not through a formal decision of a judicial body, but following an agreement between the parties which in Japanese law is mediated through the intervention of a judge, a part-time judicial officer (Choutei-kan) identified among lawyers with at least five years of experience, who conducts the procedure with the same authority as the judge, or through the intervention of a Conciliation Committee composed of a judge or an officer and two or more Conciliation Commissioners identified among ordinary people.

It must be said that in western countries there is a certain Myth ${ }^{8}$ regarding the reasons for the spread of conciliation in the Japanese system.

The development of conciliation, in Japan as an alternative dispute resolution tool to the judiciary, must be traced, not so much to character-emotional conditions typical of the Japanese social reality, but perhaps to more structural reasons: i) historical reasons. Since the Meiji government there has been an attention of the authorities to encourage forms of out-of-court mediation organized for the resolution of

8 Halley, The spirit of japanese law, London, 1999, in part. p. 13 ss.; Haley, The Myth of the Reluctant Litigant, in Journal of Japanese Studies, 1978, 4, p. 359 ss; Oda, Japanese Law, 2003, $2^{\circ}$ ed., p. 6; TIMOTEO, Il contratto in Cina e Giappone nello specchio dei diritti occidentali, Padova, 2004, p. 216 ss.; A. Ortolani, Il giri e la questione della mentalità giuridica giapponese, in Riv. dir. civ., 2009, p. 371 ss. 
disputes; ii) reasons related to the time and costs of the proceedings; iii) reasons based on the distance of the Courts from individuals for emotional factors such as the atmosphere of the court, the language and the formal clothes of the judges; iv) reasons related to the existence of social sanctions for litigation 9.

The tendency to settle disputes, even with uneconomic results for the party in conflict who in a court could have found a more favorable legal solution, derives not from a sort of innate sense of love for neighbor and a propensity for conciliation, but by the cultural need to maintain good relations with the rest of the community.

The latter profile brings us back to the relevance in Japanese culture of the "sekentei" translatable as "social appearance", as "external way of relating to others"10.

Beyond what may be the reasons for the development of ADR in Japan, there is no doubt that the inclusion of ADR in the solution of conflicts has a strong impact as the loled of conceiving law as a tool for ordering the society and not there is no doubt that in Japan the use of ADR is noteworthy.

The judge primarily decides the dispute through the application of the law.

The conciliator or the Conciliation Committee does not resolve the dispute through the application of rules, but they favor its settlement by registering the agreement reached between the parties.

Alongside the "wa", the "jori" and the "giri", the importance of ADR in resolving disputes in Japan is also another element of "detachment" between the legal system and the law.

Social reality is regulated by an orderly system of rules of conduct far from the fixity of the legislative text and closer to the peculiarities of the interests in the single case.

This perspective is of particular interest in western countries where attention to mediation in dispute resolution is raising. The practice of law has new shape related to the so-called "vanishing trial". With this expression ${ }^{11}$ scholars indicate a situation of increasing of the use of negotiation, also thanks to interventions of the legislator, and a view of legal reasoning not only in terms of rights based disputes resolution.

\section{4.}

At this point we will try to consider whether and how the "spirit of Japanese law" may affect the idea of a contract in Japan.

Let's start by reporting the opinions of two scholars who have largely contributed to the spread of knowledge of Japanese law in the western world.

Noda observes that in general the Japanese have a critical approach in the formation of the contract 12 . The Japanese contractor does not have the exact awareness of engaging with the stipulation of a contract, does not have in mind the effects of the contract and does not realize that he will be bound by the contractual obligations that he has voluntarily assumed. In short, he does not feel bound by the contract.

Similarly, Professor Kawashima, starting from the assumption that the Japanese do not have a sense

\footnotetext{
9 Kawashima, Dispute Resolution in Contemporary Japan, in Law in Japan. The Legal Order in Changing Society, a cura di Taylor von Mehren, Cambridge, Massachusetts, 1963, p. 52 ss.; RYUZAKI, Saiban to giri-ninjo (Litigation and giri-humanity). Tokyo, 1988, p. 2 ss.

10 Inoue, Seken-tei no kōzō (The structure of social appearances), Tokyo, 1977, p. 91.

11 Mark Galanter, The Vanishing Trial: An Examination of Trials and Related Matters in Federal and State Courts, 1 J. OF EMPIRICAL LEGAL STUDIES 459 (2004); Julie Macfarlane, Evolution of the New Lawyer: How Lawyers are Reshaping the Practice of Law, The, 2008 J. Disp. Resol. (2008). Se also M. Henssler and S. Landini, Introduction, Lawyers in Italy. Challenge the change, DeutsherAnwaltVerlag, 2020, p. 3.

12 Noda, Japanese Law Studies, Paris, 1966, p. 54.
} 
of law, concluded that it is well known that Americans are more respectful of the agreements of the Japanese. The Americans are quite clear that failure to execute the contract matters responsibility ${ }^{13}$.

It seems that according to the Japanese culture of dealing contracts, the agreement is sealed not so much by the formal conclusion of the contract, but by the trust that has been created between the two contractors. From these factors of the human relationship created between the two contractors arise those behavioral duties for the contracting parties who settle the relationship before and more of the contract formally completed.

It is generally noted that the Japanese tend not to conclude detailed contracts. The contract is considered by them as a mere communion of declarations of intent towards a goal represented by the execution of the relationship.

The "ishi-hyouji", literally "declaration of intent", is a central notion in Japanese contract law.

The possible conduct of the relationship is not regulated in terms of liability, penalties clauses, termination clauses, clauses on time and place of the execution of the contract, methods of delivery and so on.... Everything is left to a discipline that is made up step by step thanks to observance of the duties of conduct of the "giri", and above all of the "wa" as well as from the principle of "shingi seijitsu" "justice in relationships", translated as "good faith", in the west also includeninar 1 of Japanese civil code. The bond does not originate from the contract, but from the relationship which has found its rule in the aforementioned principles.

It is however possible to observe, first of all, an evolution of contemporary Japanese contract law which has brought about an approach of this to western systems and which has led to a progressive greater sensitivity for individual subjective situations. We must say that on April 1, 2020, the Act to Partially Amend the Civil Code ("Amendment") will come into effect. The Amendment should change the provisions dealing with the law of obligations (including law of contracts) for the first time in about 120 years since the Civil Code was enacted.

In principle, the Amendment will apply to contracts that are executed on or after the effective date of April 1, 2020 (Article 34, Paragraph 1 of Appendix to the Amendment).

In more recent times, it has become the practice, among Japanese operators, to follow two bargaining models:

- "short" and informal bargaining for national relations;

- detailed and formal bargaining for international relations.

Indeed, it is possible to highlight that in international contracts there is a real obsession with detail and respect for literality, so that the possibility of extratextuality in the interpretation of the contract is reduced to a mere formal practice.

It can also be observed in Japanese law a certain liability of the contractual bond, asserted by the aforementioned authors, and the tendency to avoid breaking relationships even if not based on a formal contractual bond seems to be discernible. It seems that the Japanese do not perceive the contract as the true constitutive moment of the bond. They feel the existence of bonds beyond the completion of the contract formation process.

In this regard, we have considered how judicial decisions tends to recognize relationships between

13 Kawashima, The legal consciousness of contract in Japan, in Japanese law and legal theory, a cura di Fujikura, Aldershot, Singapore, Sydney, 1996, p. 35 ss. 
private individuals.

There is a tendency in Japanese law to consider the proposals as firm. See the provisions of art. 525 of the civil code: "The proposer cannot revoke a proposal to a distant person, without a deadline for acceptance, until a reasonable time has passed for the receipt of the news of acceptance".

We are therefore in the presence of a regime very close to the German one and very distant from the Italian one which recognizes as a general rule that of the freedom of withdrawal from negotiations within the limits of good faith.

It remains to be seen whether the commonality with the German system is justified only for historical reasons or also for cultural reasons.

The withdrawal from negotiations in commercial contracts is also limited. In these cases, it differs according to whether the offer is made in the presence of the counterparty or not ${ }^{14}$. In the case of a proposal between distant people, however, the proposal loses its effectiveness if it has not been accepted within a reasonable period of time (art. 508 of the commercial code).

However, these rules do not establish greater freedom in commercial negotiations, in fact, based on art. 509 of the Japanese commercial code "Obligation of Notification of Rejection or Acceptance" is expected that: "When a merchant-trader receives an offer of contract which falls within a sector of his business from a party with whom he engages in regular business transactions, he must send a notice of acceptance or rejection without delay. If he fails to send such notice he shall be considered as having accepted".

Thus a conception of the relationship that is established in the negotiations seems to emerge, which can perhaps be explained by the sense of community that we were talking about when we dealt with the spirit of Japanese law.

The sense of community based on the principles of "wa", in the contractual context, leads to reviewing the possibility of leaving the relationship not only from contractual relationships but also from those noncontractual or pre-contractual relationships constituting, however, constraints based on the rules of good performance of relationships between individuals. Japanese judges tend not only to deny, based on the principle of "good faith" "shingi seijitsu" in article 1 civil code, the free termination of negotiations, but also the non-renewal of contractual relations. According to the principle of "good faith" "shingi" in article 1 civil code, Japanese judges tend not only to deny, the free termination of negotiations, but also the nonrenewal of contractual relations, as we are going to see with regard to the Sendai Court case of 199415 .

Generally speaking as in the Japanese legal system: the relationship exists beyond the contract and this relationship does not need rules based on the law or on the autonomy of the parties because it is governed by the principles of "trust" and good faith according to article 1 of the unicode.

It is true that even in the western legal systems a state of fluidity between contractual and noncontractual obligations is increasingly being recognized. In particular, in the civil law countries, where the barriers between the two areas (contract and extra contract) were more consistent, gaps were

\footnotetext{
14 In the event of a proposal in presence, the offer loses its effectiveness if it is not accepted (art. 507 of the past commercial code). In the article 507 of commercial law, one clause, "contract application between interlocutors", has been deleted. In the paragraph 2 of article 508 of commercial law, "the article 523 of civil law" has been changed to "the article 524 of civil law". The article 509 of commercial law didn't change. An helpful data base of Japanese law is http://japaneselawtranslation.go.jp/?re $=01$

15 CHINO, KASHIWAGI e OKADA, in Japanese Business Law, Austin-Boston-Chicago-New York-TheNetherlands, 2007, p. 178
} 
identified anyway by reducing the distances between the rules that govern them, or by extending the areas of contract.

The rules of "good faith" which conform relations in Japan even if not consolidated in a contractual bond, are, however, far more invasive than the individual sphere compared to the good faith in negotiations as conceived in western countries. Referring to art. 1 of the civil code, the Japanese judges come to recognize the establishment of a contractual bond in the absence of the parties will or to impose the continuation of extinct relationships based on the contract duration rules established by the parties.

The Sendai District Court 30/9/1994 decided that, on the basis of the principle of good faith, the series of contracts should be seen as a single indefinite contract which could be terminated within a reasonable period of time.

Also in this case, in accordance with the principle of good faith, the existence of a bond beyond the letter of the contract is sanctioned.

The term "good faith" is also referred to as the ordering principle for the good performance of contractual relationships in the so-called Good faith negotiation clauses or under those contractual conditions under which "Should a disagreement regarding this contract arise, the two parties will discuss it with good faith" 16 .

This clause is then usually accompanied by a postponement to conciliation or to arbitration, with particular regard to international contracts, even if the latter is associated with the judicial process and considered a solution to a condition of irreparable break between the parties.

Even in our legal system, in which the principle of free withdrawal from negotiations is in force, the rule of good faith binds the parties not to revoke their negotiating statements unjustifiably. The consequences of an unjustified withdrawal from the negotiations, after expectations have been created in the counterparty regarding the next conclusion of the contract, are explained, however, only in compensation, not also in the sense of considering the contract concluded ${ }^{17}$.

These considerations help us to read carefully those norms of the Japanese civil code in which the legislator in referring to proposal and acceptance speaks generically of "manifestation of intent".

Let's consider the text of art. 527 of the Japanese civil code on the moment of formation of the contract $^{18}$. Here is the term "ishi hyôji", on which we have already had occasion to dwell, which literally means "manifestation of intent". It would be spontaneous to translate the term, since it refers to proposal and acceptance, as "contractual declaration". However, given the sense of constraint that in Japan is recognized to declarations according to the good faith principle, which in Italian system would be mere "manifestations of intent", it is perhaps preferable to translate the term as declarations of intent while

16 See Kawashima, The legal consciousness of contract in Japan, in Japanese law and legal theory, a cura di Fujikura, Aldershot, Singapore, Sydney, 1996, p. 35 ss.

Un'altra formula usata è: "Both parties shall use their best efforts to resolve by mutual negotiation and agreement any disputes, controversies and differences which may occur between the parties in connection with this agreement. If such negotiation does not result in a settlement of such disputes, controversies or differences within __ days, they shall be exclusively and finally resolved through binding arbitration which (i) if requested by party A (e.g. American corporation), shall be conducted in Tokyo in accordance with the rules of the Japan Commercial Arbitration Association and (ii) if requested by party B (Japanese corporation), shall be held in New York in accordance with the rules of the American Arbitration Association."

17 Haupt, Über faktische Vertrag-verhältnisse, Lipzia, 1941.

18 Art. 527 "If no notice of acceptance is required due to the offeror's manifestation of intention or customs of the transaction, a contract is formed upon the occurrence of any fact which should be regarded as a manifestation of intention of acceptance." 
maintaining its literal meaning.

5.

From these disciplinary profiles then considerations emerge, which move beyond the sense of community found in Japanese private law, and lead to reflections on the same translation-interpretation of the legal texts.

If normally, as regards the legal translation, it has been underlined how the real problem is given by the fact that two terms, belonging to different languages, may correspond in the common signifier but not in the judicial one for which we end up recording "an equivalence linguistics and legal diversity", in the case of the translation of Japanese legal texts there is perhaps a different problem.

We find ourselves in the presence of a legal system composed of terms which are the translation into Japanese of concepts close to the Italian legal system because of a Franco / German matrix for the historical reasons highlighted and which therefore lend themselves to be easily translated into the corresponding Italian legal terms. The conceptual closeness between these systems poses problems as in the translation into Italian there is the risk of losing sight of the significance of the Japanese ideographic representations in which the western juridical concepts, their history, the socio-cultural profiles absorbed by them were transposed. Here we could then repeat what has been observed, with regard to Japanese philosophical language, by an Italian scholar "not infrequently the dialogue between western philosophers (but the same, we add, may apply to jurists) and Japanese reveals a double monologue in which both interlocutors; while using similar languages, they make different assumptions prevail "19.

Hence the particular importance, in reading Japanese legal texts, of adherence to the letter and the contribution of experts in Japanese history, culture and language; without thereby wanting to exclude the weight that these conditions generally have in the translation of legal texts.

19 This consideration corresponds to what has recently been stated with regard to the ways in which Japanese neologisms representative of western philosophical concepts were created. "The transition from alphabetic-phonetic languages to the so-called ideographic language does not only affect the individual terms, but involves, as we have begun to see, the transposition from one conception of the language to another ... The terms used today in Japanese philosophical language are were devised by translating them from Western languages (in particular from German and English) on the basis of an interpretation of the sense in which those terms were used in the West ": FORZANI, I fiori del vuoto. Introduzione alla filosofia giapponese, Torino, 2006, p. 18. 